\title{
Potential role of pre- and postnatal testosterone levels in attention-deficit/hyperactivity disorder: is there a sex difference?
}

This article was published in the following Dove Press journal:

Neuropsychiatric Disease and Treatment

16 May 2017

Number of times this article has been viewed

\author{
Liang-Jen Wang ${ }^{1,2}$ \\ Miao-Chun Chou' \\ Wen-Jiun Chou' \\ Min-Jing Lee' \\ Sheng-Yu Lee ${ }^{3,4}$ \\ Pao-Yen $\operatorname{Lin}^{5}$ \\ Yi-Hsuan Lee' \\ Yi-Hsin Yang ${ }^{6}$ \\ Cheng-Fang Yen ${ }^{2,7}$ \\ 'Department of Child and Adolescent \\ Psychiatry, Kaohsiung Chang Gung \\ Memorial Hospital and Chang Gung \\ University College of Medicine, \\ ${ }^{2}$ Department of Psychiatry, School \\ of Medicine, and Graduate Institute \\ of Medicine, College of Medicine, \\ Kaohsiung Medical University, \\ ${ }^{3}$ Department of Psychiatry, Kaohsiung \\ Veterans General Hospital, Kaohsiung, \\ ${ }^{4}$ Department of Psychiatry, College \\ of Medicine and Hospital, National \\ Cheng Kung University, Tainan, \\ ${ }^{5}$ Department of Psychiatry, Kaohsiung \\ Chang Gung Memorial Hospital and \\ Chang Gung University College \\ of Medicine, ${ }^{6}$ School of Pharmacy, \\ Kaohsiung Medical University \\ Hospital, ${ }^{7}$ Department of Psychiatry, \\ Kaohsiung Medical University \\ Hospital, Kaohsiung, Taiwan
}

Correspondence: Cheng-Fang Yen Department of Psychiatry, Kaohsiung Medical University Hospital, 100 Tzyou First Road, Kaohsiung 807, Taiwan

Tel $+88673121 \quad 1019$

Fax +886 73212062

Email chfaye@cc.kmu.edu.tw
Objective: Both prenatal testosterone (T) exposure and postnatal $\mathrm{T}$ levels have been associated with developing neural circuitry and behavioral systems. This study examined the potential correlation between pre- and postnatal $\mathrm{T}$ levels and behavioral and neurocognitive profiles of children with attention-deficit/hyperactivity disorder (ADHD).

Methods: Two hundred ADHD patients with a mean age of $8.7 \pm 2.0$ years (158 boys and 42 girls) were recruited. The ratio of the length of the right index finger (2D) to that of the right ring finger (4D) (2D/4D ratio) served as a surrogate of prenatal $\mathrm{T}$ exposure, and postnatal $\mathrm{T}$ was determined using salivary $\mathrm{T}$ concentration. Behavioral symptoms were evaluated using the Swanson, Nolan, and Pelham - Version IV Scale for ADHD (SNAP-IV). Neurocognitive function was assessed using the Wechsler Intelligence Scale for Children - Fourth Edition (WISC-IV) and Conners' Continuous Performance Test (CPT).

Results: Lower 2D/4D ratios were associated with comorbid disruptive behavior disorders $(t=2.15, P=0.033$ ) in all participants. Among the boys with ADHD, neither 2D/4D ratios nor salivary $\mathrm{T}$ levels were associated with behavioral symptoms or neurocognitive function. Among the girls with ADHD, the salivary T level was positively correlated with the Perceptual Reasoning Index of the WISC-IV $(r=0.48, P=0.001)$ and the Confidence Index $(r=0.37, P=0.017)$ and Omission Errors of the CPT ( $r=0.62, P<0.001)$.

Conclusion: Findings suggest that a higher prenatal T exposure is associated with a greater risk of developing disruptive behavior disorders, and T may exert differential neurocognitive effects between boys and girls with ADHD. However, the neurobiological mechanisms of T involved in the pathogenesis of ADHD warrant further investigation.

Keywords: ADHD, endocrinology, cognition, psychopathology, comorbidity

\section{Introduction}

Attention-deficit/hyperactivity disorder (ADHD), which is characterized by inattention, hyperactivity, and impulsivity, is one of the most prevalent neuropsychiatry disorders among children. ADHD is estimated to affect 3\%-10\% of school-age children worldwide. ${ }^{1}$ The prevalence of ADHD is substantially different between the sexes: reported ratios of boys to girls range from $4: 1$ to $9: 1 .^{2}$ In addition to prevalence rates, sex differences in the behavioral features and neuropsychological profiles of patients with ADHD have been widely debated. ${ }^{3-5}$ On the basis of observations of sex differences, many researchers have raised questions with respect to the potential roles of the neuroendocrine system in the etiology of ADHD. ${ }^{6-8}$ Testosterone (T) is a main sex hormone produced by the testicles and the adrenal glands and is important for the proper development of male sexual characteristics. ${ }^{9}$ Both prenatal $\mathrm{T}$ exposure and 
postnatal $\mathrm{T}$ levels have been associated with developing neural circuitry and behavioral systems. ${ }^{10,11}$

High levels of prenatal $\mathrm{T}$ may affect the dopaminergic neural circuitry and decelerate neural development globally. ${ }^{12}$ A commonly used surrogate index of prenatal $\mathrm{T}$ exposure is the ratio of the length of the right index finger (2D) to that of the right ring finger (4D) (2D/4D ratio). ${ }^{13,14}$ A lower 2D/4D ratio usually represents a higher level of intrauterine $\mathrm{T}$ exposure (relative to estrogen). ${ }^{15}$ Several studies suggested that individuals with a lower, more maletypical, 2D/4D ratio tend to exhibit more prominent ADHD features. ${ }^{16-19}$ These studies support the hypothesis that prenatal $\mathrm{T}$ exposure contributes to the development of ADHD in children. However, some researchers have not found associations between 2D/4D ratios and ADHD features or externalizing behavior problems in children. ${ }^{20-22}$ In sum, whether prenatal $\mathrm{T}$ exposure plays a role in the etiology of ADHD is still open to debate.

Postnatal $\mathrm{T}$ activation from childhood to puberty potentially influences behavioral and physiological change, as well as neurodevelopment. ${ }^{23,24}$ Postnatal $\mathrm{T}$ levels are usually determined by analyzing the current (activational) $\mathrm{T}$ concentration in saliva or peripheral blood. ${ }^{25}$ Several studies have investigated the relationship between current $\mathrm{T}$ level and ADHD. For example, Herguner et $\mathrm{al}^{26}$ reported that women with polycystic ovary syndrome (an endocrine disorder that manifests hyperandrogenism) had more ADHD symptoms than did control subjects. Furthermore, higher $\mathrm{T}$ levels in saliva or in plasma have been observed in children with aggressive tendencies compared with those without aggressive tendencies. ${ }^{27-29}$ In contrast, Dorn et $\mathrm{al}^{30}$ suggested that no significant association is found between salivary T levels and children's disruptive behavior disorders (DBD). To date, evidence about the connection of current $\mathrm{T}$ levels to the pathogenesis of ADHD remains scarce and inconsistent.

Peripheral $\mathrm{T}$ levels are similar among boys and girls during early childhood, ${ }^{31}$ but $\mathrm{T}$ levels notably increase in prepubertal boys. ${ }^{9}$ During this period, the activation of preformed brain structures leads to sexually dimorphic, physical, behavioral, and cognitive alterations. ${ }^{10}$ Therefore, we proposed that $\mathrm{T}$ may be involved in the pathogenesis of sex-biased neuropsychiatric disorders, such as ADHD. However, few studies have simultaneously investigated the potential roles of prenatal and postnatal $\mathrm{T}$ exposure on the clinical features of ADHD. In addition, how $\mathrm{T}$ influences the neurocognitive function in patients with ADHD and whether there is a sex difference in the relationship between $\mathrm{T}$ and $\mathrm{ADHD}$ presentations remains poorly understood. The purpose of this study was to examine the potential correlations between $T$ levels, both pre- and postnatal and behavioral and neurocognitive profiles of patients with ADHD. We also explored whether a sex difference in such a correlation is also present.

\section{Methods}

\section{Study participants}

The study protocol was approved by the Institutional Review Board of Chang Gung Hospital in Taiwan (IRB No 1014835A3). All procedures performed in this study involving participants were in accordance with the ethical standards of the institutional and/or national research committee and with the Helsinki Declaration. We obtained written informed consent from the parents or guardians of all the participating children.

Eligible patients with ADHD treated in the outpatient Department of Child Psychiatry at a medical center in Taiwan were recruited for this cross-sectional study from August 2013 to December 2015. The inclusion criteria were 1) clinical diagnosis of ADHD by a senior child psychiatrist based on the criteria of the Diagnostic and Statistical Manual of Mental Disorders, Fourth Edition, Text Revision (DSM-IV-TR) after structured interviews based on the Chinese version of the Schedule for Affective Disorders and Schizophrenia for School-Age Children, epidemiologic version (K-SADS-E); ${ }^{32} 2$ ) age between 6 and 16 years; 3 ) being Han Chinese; and 4) new diagnosis of ADHD in a drug-naïve patient or one who had an existing diagnosis but had not used an ADHD medication in the previous 6 months or longer. Patients were excluded if they had a history of comorbid pervasive developmental disorder, intellectual disability, major depressive disorder, bipolar disorder, psychosis, epilepsy, or brain injury. In total, 203 patients with ADHD were recruited into this study.

\section{Assessments of prenatal T exposure and salivary $T$ levels}

Finger-length ratios are often used as a surrogate measure of prenatal hormone levels. ${ }^{13}$ Lengths of fingers of all participants were measured by a research assistant. Lengths of fingers were measured from the connection to the palm to the tip of the finger. The 2D/4D ratios were computed in this study because they are the best established and best replicated with respect to human behavioral sex differences. ${ }^{14}$

Saliva samples of ADHD patients were collected at 8:00 am in the outpatient department using the passive drool method; patients were instructed to avoid excessive levels 
of physical activity during the preceding 24-hour and to maintain an overnight fast before saliva collection. Saliva samples were collected in collecting tubes, immediately placed on ice, and then stored at $-80^{\circ} \mathrm{C}$ until further analysis. Salivary $\mathrm{T}$ levels were quantified using a chemiluminescence immunoassay (IB57403; IBL-America, Minneapolis, MN, USA). The sensitivity of detection of this method was $1.0 \mathrm{pg} / \mathrm{mL}$. The intra- and interassay coefficients of variation were $2.9 \%-7.0 \%$ at $21-557 \mathrm{pg} / \mathrm{mL}$ and $1.5 \%-3.2 \%$ at 38-541 pg/mL, respectively.

\section{Clinical measurements}

Each ADHD patient was interviewed by a senior psychiatrist who used the K-SADS-E diagnostic tool. An experienced child psychologist conducted the Wechsler Intelligence Scale for Children - Fourth Edition (WISC-IV) and Conners' Continuous Performance Test (CPT) with individual patients in a room dedicated to reducing variability in testing conditions. The Swanson, Nolan, and Pelham - Version IV Scale (SNAP-IV) parent form and SNAP-IV teacher form were completed by the patient's parents and a teacher, respectively.

The K-SADS-E is a semistructured diagnostic interview that is designed to assess current and past episodes of psychopathology in children and adolescents according to DSM-IIIRevised (DSM-III-R) and DSM-IV criteria. ${ }^{32}$ The K-SADS-E is administered by interviewing the parent(s) and the child and finally achieving summary ratings that include all sources of information. The validity and reliability of the Chinese version of K-SADS-E have been established in Taiwan. ${ }^{33}$

The WISC-IV Chinese version is an individually administered and norm-referenced instrument designed to measure the intelligence of children aged from 6 to 16 years. ${ }^{34}$ The WISC-IV contains 10 core and 5 supplemental subtests. The core subtests are used to form 4 factor indexes, including the Verbal Comprehension Index (VCI), the Perceptual Reasoning Index (PRI), the Working Memory Index (WMI), and the Processing Speed Index (PSI). The Full-Scale Intelligence Quotient (FSIQ) is also formed from the 10 core subtests. The factor indexes and FSIQ each has a population mean of 100 and a standard deviation of $15 .^{35}$

The SNAP-IV is a 26-item questionnaire that is used to evaluate ADHD symptoms and severity and is completed by parents or teachers. ${ }^{36}$ The 26 items include 18 for ADHD symptoms ( 9 for inattentive and 9 for hyperactive/impulsive) and 8 for oppositional defiant disorder (ODD) symptoms as defined in DSM-IV. Each item is scored on a 0-3 Likert scale. The Chinese version of the SNAP-IV parent form ${ }^{37}$ and the
SNAP-IV teacher form ${ }^{38}$ were reported to have satisfactory levels of reliability and concurrent validity.

The CPT is a 14-minute computerized test that primarily assesses attention and impulse control. ${ }^{39}$ Briefly, participants are required to respond to the stimuli on a computer screen by pressing a space bar for every letter except the letter "X." Among the multiple dependent measures that may be used, omissions, commissions, hit reaction time, and detectability are the most commonly used indices. The T-score of the $\mathrm{CPT}$, in which a lower T-score indicates better performance, is commonly used in research analyses. The Confidence Index (percentile) showed the integration of all the CPT data obtained from test administration to provide a chance out of 100 that a significant attention problem existed..$^{40}$

\section{Statistical analysis}

Data were analyzed using the statistical software package SPSS, version 16.0 (SPSS Inc., Chicago, IL, USA). Variables are presented as either the mean (standard deviation) or frequency. In 3 patients, the salivary $\mathrm{T}$ levels were undetermined, and they were excluded from the analysis. Categorical variables among male and female patients were compared using either the chi-square test or Fisher's exact test, depending on case numbers, and an independent $t$-test was used to compare continuous variables between groups. Pearson correlation was performed to analyze the relationships between 2D/4D ratios, salivary $\mathrm{T}$ levels, clinical symptoms, and neuropsychological functions measured by the CPT and WISC-IV, respectively. Two-tailed $P$-values of $<0.05$ were considered statistically significant.

\section{Results}

A total of 200 ADHD patients (mean age 8.7 \pm 2.0 years) were recruited into this study. Of these patients, $158(79 \%)$ were boys and 42 (21\%) were girls; 60 of them (30\%) were classified as inattentive type, and 140 (70\%) were classified as hyperactive-impulsive type or combined type. In terms of psychiatric comorbidities, 35 (17.5\%) patients had comorbid ODD, 2 (1\%) had conduct disorder, $18(9 \%)$ had tic disorders, $4(2 \%)$ had sleep disorders, and $9(4.5 \%)$ had anxiety disorders. Compared to the girls (Table 1), boys were taller ( $t=3.08, P=0.002$ ), heavier ( $t=3.07, P=0.002$ ), have higher body mass index (BMI) $(t=2.34, P=0.023)$, more likely to be ADHD hyperactive/impulsive or combined type $\left(\chi^{2}=4.19\right.$, $P=0.041)$, have higher VCI scores on the WISC-IV ( $t=2.31$, $P=0.022$ ), and have higher teacher-rated hyperactivity/ impulsivity scores $(t=4.37, P<0.001)$ and oppositional scores on the SNAP-IV $(t=3.33, P=0.001)$. 
Table I Characteristics of patients with ADHD and comparison of male and female patients

\begin{tabular}{|c|c|c|c|c|}
\hline Variables & Males $(n=158)$ & Females $(n=42)$ & Statistical values $^{a}$ & $P$-value \\
\hline Age (years) & $8.8 \pm 2.1$ & $8.3 \pm 1.7$ & $t=1.199$ & 0.232 \\
\hline Height $(\mathrm{cm})$ & $133.7 \pm 13.9$ & $126.7 \pm 9.8$ & $t=3.082$ & $0.002 * *$ \\
\hline Weight (kg) & $33.5 \pm 11.1$ & $27.8 \pm 9.8$ & $t=3.066$ & $0.002 * *$ \\
\hline Body mass index $\left(\mathrm{kg} / \mathrm{m}^{2}\right)$ & $18.3 \pm 3.2$ & $16.9 \pm 3.6$ & $t=2.338$ & $0.023 *$ \\
\hline \multicolumn{5}{|l|}{ ADHD subtypes, $n(\%)$} \\
\hline Inattentive type & $42(26.6)$ & $18(42.9)$ & $\chi^{2}=4.185$ & $0.04 I^{*}$ \\
\hline Hyperactive/impulsive or combined type & $116(73.4)$ & $24(57.1)$ & & \\
\hline \multicolumn{5}{|l|}{ Comorbidities, n (\%) } \\
\hline Oppositional defiant disorder & $31(19.6)$ & $4(9.5)$ & $\chi^{2}=2.343$ & 0.126 \\
\hline Conduct disorder & $2(1.3)$ & $0(0)$ & $\chi^{2}=0.537$ & 0.464 \\
\hline Tic disorders & $14(8.9)$ & $4(9.5)$ & $\chi^{2}=0.018$ & 0.894 \\
\hline Sleep disorders & $4(2.5)$ & $0(0)$ & $\chi^{2}=1.085$ & 0.298 \\
\hline Anxiety disorders & $7(4.4)$ & $2(4.8)$ & $\chi^{2}=0.008$ & 0.927 \\
\hline \multicolumn{5}{|l|}{ WISC-IV } \\
\hline Full Scale Intelligence Quotient & $95.5 \pm 12.2$ & $91.9 \pm 12.7$ & $t=1.705$ & 0.090 \\
\hline Verbal Comprehension Index & $99.6 \pm 11.6$ & $94.9 \pm 11.9$ & $t=2.314$ & $0.022 *$ \\
\hline Perceptual Reasoning Index & $95.8 \pm 15.1$ & $92.9 \pm 13.7$ & $t=1.126$ & 0.261 \\
\hline Working Memory Index & $96.6 \pm 13.4$ & $94.1 \pm 13.9$ & $t=1.046$ & 0.297 \\
\hline Processing Speed Index & $93.8 \pm 14.5$ & $91.6 \pm 13.5$ & $t=0.877$ & 0.381 \\
\hline \multicolumn{5}{|l|}{ Clinical measures } \\
\hline SNAP-IV parent form (I) & $15.0 \pm 5.3$ & $16.2 \pm 4.8$ & $t=-1.329$ & 0.185 \\
\hline SNAP-IV parent form $(\mathrm{H})$ & $13.4 \pm 5.8$ & $12.1 \pm 6.3$ & $t=1.24 \mid$ & 0.216 \\
\hline SNAP-IV parent form (O) & $10.9 \pm 5.7$ & $9.9 \pm 5.3$ & $t=1.006$ & 0.315 \\
\hline SNAP-IV teacher form (I) & $|4.3 \pm 6|$. & $|3.0 \pm 6|$. & $t=1.188$ & 0.236 \\
\hline SNAP-IV teacher form $(\mathrm{H})$ & $12.1 \pm 7.2$ & $6.8 \pm 6.6$ & $t=4.369$ & $<0.00 I^{* * *}$ \\
\hline SNAP-IV teacher form (O) & $7.8 \pm 6.2$ & $4.4 \pm 4.7$ & $t=3.332$ & $0.001 * *$ \\
\hline \multicolumn{5}{|l|}{ Indices of CPT } \\
\hline Confidence Index & $58.6 \pm 21.0$ & $53.4 \pm 23.5$ & $t=1.426$ & 0.155 \\
\hline Omission & $59.1 \pm 26.6$ & $58.3 \pm 24.1$ & $t=0.173$ & 0.863 \\
\hline Commission & $50.4 \pm 9.9$ & $51.5 \pm 9.4$ & $t=-0.652$ & 0.515 \\
\hline Hit reaction time & $54.7 \pm 12.1$ & $56.5 \pm 13.0$ & $t=-0.817$ & 0.415 \\
\hline Detectability & $51.2 \pm 9.0$ & $52.7 \pm 10.9$ & $t=-0.884$ & 0.378 \\
\hline
\end{tabular}

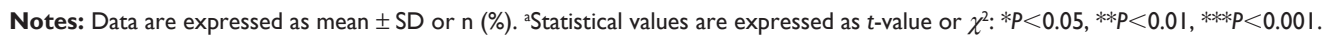

Abbreviations: ADHD, attention-deficit/hyperactivity disorder; CPT, Conners' Continuous Performance Test; H, hyperactivity/impulsivity scores; I, inattention scores; O, oppositional scores; SD, standard deviation; SNAP-IV, Swanson, Nolan, and Pelham - Version IV Scale for ADHD; WISC-IV, Wechsler Intelligence Scale for Children Fourth Edition.

Of the total 200 patients with ADHD, the mean $2 \mathrm{D} / 4 \mathrm{D}$ ratios and salivary $\mathrm{T}$ levels were $96.1 \% \pm 4.6 \%$ and $50.1 \pm 79.4 \mathrm{pg} / \mathrm{mL}$, respectively. Patients' salivary T levels were not significantly correlated with their $2 \mathrm{D} / 4 \mathrm{D}$ ratios $(r=0.09, P=0.229)$. Table 2 lists the relationships between 2D/4D ratios and salivary T levels between sexes, ADHD subtypes, and comorbidities. Patients with comorbid DBD (ODD or conduct disorder) had lower 2D/4D ratios than did their counterparts without a comorbidity $(t=2.15, P=0.033)$. The salivary $\mathrm{T}$ levels of ADHD boys were significantly higher than those of ADHD girls ( $t=2.04, P=0.043$ ).

Table 3 summarizes the correlations between 2D/4D ratios, salivary T levels, patients' characteristics, and neuropsychological function among ADHD patients, stratified by sex. In both sexes, the 2D/4D ratios were not correlated with any clinical measure or neuropsychological performance. Among the boys with ADHD, salivary T levels were positively correlated with age $(r=0.22, P=0.005)$, height ( $r=0.22, P=0.005)$, body weight $(r=0.24, P=0.003)$, and BMI ( $r=0.17, P=0.036$ ), but they did not correlate with clinical symptoms and neurocognitive performance. Among girls with ADHD, salivary $\mathrm{T}$ levels positively correlated with the PRI scores on the WISC-IV ( $r=0.48, P=0.001)$, Confidence Index $(r=0.37, P=0.017)$, and Omission Errors of the CPT $(r=0.62, P<0.001)$.

\section{Discussion}

The findings in this study indicate that prenatal $\mathrm{T}$ exposure, using the $2 \mathrm{D} / 4 \mathrm{D}$ ratio as a surrogate index, is not associated with ADHD clinical symptoms or neuropsychological 
Table 2 Ratios of 2D/4D and salivary testosterone levels between sex and ADHD subtypes and comorbidities among ADHD patients

\begin{tabular}{|c|c|c|c|c|c|c|}
\hline \multirow[t]{2}{*}{ Variables } & \multicolumn{3}{|l|}{ 2D/4D ratio } & \multicolumn{3}{|l|}{ Salivary testosterone } \\
\hline & Mean \pm SD (\%) & $t$ & $P$-value & Mean \pm SD $(p g / m L)$ & $t$ & $P$-value \\
\hline \multicolumn{7}{|l|}{ Sex } \\
\hline Males $(n=158)$ & $96.1 \pm 4.7$ & 0.275 & 0.784 & $54.2 \pm 86.1$ & 2.043 & $0.043^{*}$ \\
\hline Females $(n=42)$ & $95.9 \pm 4.3$ & & & $34.6 \pm 43.5$ & & \\
\hline \multicolumn{7}{|l|}{ ADHD subtypes } \\
\hline Inattentive type $(n=60)$ & $97.0 \pm 4.5$ & 1.868 & 0.063 & $43.2 \pm 55.3$ & -0.798 & 0.426 \\
\hline $\mathrm{H} / \mathrm{I}$ or combined type $(\mathrm{n}=\mid 40)$ & $95.7 \pm 4.6$ & & & $53.0 \pm 87.8$ & & \\
\hline \multicolumn{7}{|l|}{ ODD or conduct disorder } \\
\hline With $(n=36)$ & $94.6 \pm 6.0$ & -2.145 & $0.033^{*}$ & $53.7 \pm 118.7$ & 0.298 & 0.766 \\
\hline Without $(n=164)$ & $96.4 \pm 4.2$ & & & $49.3 \pm 68.4$ & & \\
\hline \multicolumn{7}{|l|}{ Tic disorders } \\
\hline With $(n=18)$ & $96.1 \pm 4.8$ & -0.023 & 0.982 & $30.9 \pm 42.8$ & -1.075 & 0.284 \\
\hline Without $(n=\mid 82)$ & $96.1 \pm 4.6$ & & & $52.0 \pm 82.0$ & & \\
\hline \multicolumn{7}{|l|}{ Anxiety disorders } \\
\hline With $(n=9)$ & $95.4 \pm 4.2$ & -0.455 & 0.650 & $95.8 \pm 111.3$ & 1.775 & 0.077 \\
\hline Without $(n=|9|)$ & $96.1 \pm 4.6$ & & & $47.9 \pm 77.3$ & & \\
\hline
\end{tabular}

Note: $* p<0.05$.

Abbreviations: $2 D / 4 D$ ratio, ratio of the length of the right index finger (2D) to that of the right ring finger (4D); ADHD, attention-deficit/hyperactivity disorder; $\mathrm{H}$, hyperactivity/impulsivity scores; I, inattention scores; ODD, oppositional defiant disorder; SD, standard deviation.

Table 3 Correlations among 2D/4D ratios, salivary testosterone levels, patients' characteristics, and neuropsychological functions among ADHD patients

\begin{tabular}{|c|c|c|c|c|c|c|c|c|}
\hline \multirow[t]{3}{*}{ Variables } & \multicolumn{4}{|c|}{ 2D/4D ratio } & \multicolumn{4}{|c|}{ Salivary testosterone level } \\
\hline & \multicolumn{2}{|l|}{ Males } & \multicolumn{2}{|c|}{ Females } & \multicolumn{2}{|l|}{ Males } & \multicolumn{2}{|c|}{ Females } \\
\hline & $\boldsymbol{r}$ & $P$-value & $\boldsymbol{r}$ & $P$-value & $\boldsymbol{r}$ & $P$-value & $\boldsymbol{r}$ & $P$-value \\
\hline Age (years) & 0.114 & 0.153 & 0.115 & 0.470 & 0.222 & $0.005^{* *}$ & 0.040 & 0.801 \\
\hline Height (cm) & 0.102 & 0.200 & 0.107 & 0.501 & 0.222 & $0.005^{* *}$ & -0.127 & 0.423 \\
\hline Weight (kg) & 0.125 & 0.117 & -0.006 & 0.971 & 0.239 & $0.003^{* *}$ & -0.062 & 0.696 \\
\hline Body mass index $\left(\mathrm{kg} / \mathrm{m}^{2}\right)$ & 0.108 & 0.174 & -0.035 & 0.827 & 0.170 & $0.036^{*}$ & -0.024 & 0.882 \\
\hline \multicolumn{9}{|l|}{ WISC-IV } \\
\hline Full Scale Intelligence Quotient & 0.089 & 0.269 & -0.009 & 0.957 & 0.049 & 0.541 & 0.196 & 0.213 \\
\hline Verbal Comprehension Index & 0.078 & 0.328 & 0.072 & 0.651 & 0.021 & 0.798 & 0.092 & 0.563 \\
\hline Perceptual Reasoning Index & 0.140 & 0.078 & -0.081 & 0.608 & 0.078 & 0.327 & 0.482 & $0.001 * *$ \\
\hline Working Memory Index & 0.039 & 0.627 & 0.080 & 0.615 & 0.023 & 0.772 & 0.036 & 0.823 \\
\hline Processing Speed Index & -0.055 & 0.494 & 0.069 & 0.664 & 0.006 & 0.937 & -0.197 & 0.211 \\
\hline \multicolumn{9}{|l|}{ Clinical measures } \\
\hline SNAP-IV parent form (I) & -0.009 & 0.909 & 0.228 & 0.147 & 0.104 & 0.193 & 0.219 & 0.163 \\
\hline SNAP-IV parent form $(\mathrm{H})$ & -0.055 & 0.492 & 0.199 & 0.206 & 0.103 & 0.200 & 0.235 & 0.134 \\
\hline SNAP-IV parent form (O) & -0.021 & 0.796 & 0.066 & 0.680 & 0.103 & 0.198 & -0.056 & 0.727 \\
\hline SNAP-IV teacher form (I) & 0.111 & 0.166 & -0.202 & 0.200 & 0.057 & 0.477 & -0.060 & 0.705 \\
\hline SNAP-IV teacher form $(\mathrm{H})$ & -0.029 & 0.719 & -0.056 & 0.723 & 0.043 & 0.592 & -0.177 & 0.261 \\
\hline SNAP-IV teacher form $(O)$ & 0.021 & 0.793 & 0.158 & 0.318 & 0.082 & 0.305 & -0.091 & 0.566 \\
\hline \multicolumn{9}{|l|}{ Indices of CPT } \\
\hline Confidence Index & -0.061 & 0.448 & -0.008 & 0.962 & 0.100 & 0.211 & 0.368 & $0.017^{*}$ \\
\hline Omission & 0.029 & 0.719 & -0.034 & 0.829 & 0.053 & 0.507 & 0.622 & $<0.001 * * *$ \\
\hline Commission & -0.041 & 0.609 & -0.046 & 0.773 & -0.010 & 0.897 & -0.103 & 0.518 \\
\hline Hit reaction time & -0.031 & 0.701 & 0.076 & 0.632 & 0.004 & 0.957 & 0.089 & 0.574 \\
\hline Detectability & -0.013 & 0.873 & -0.082 & 0.604 & -0.048 & 0.547 & 0.153 & 0.334 \\
\hline
\end{tabular}

Notes: $r=$ Pearson's correlation coefficient. $* P<0.05$, $* * P<0.01$, $* * * P<0.001$.

Abbreviations: 2D/4D ratio, ratio of the length of the right index finger (2D) to that of the right ring finger (4D); ADHD, attention-deficit/hyperactivity disorder; CPT, Conners' Continuous Performance Test; H, hyperactivity/impulsivity scores; I, inattention scores; O, oppositional scores; SNAP-IV, the Swanson, Nolan, and Pelham Version IV Scale for ADHD; WISC-IV, Wechsler Intelligence Scale for Children - Fourth Edition. 
performance. We did find an association between prenatal T exposure and comorbid DBD (ODD or conduct disorder) in our sample overall, but there was no evidence for an association between 2D/4D ratio and DBD scores for either sex. Among girls with ADHD, a higher level of salivary $T$ was associated with a better performance on the PRI in the WISC-IV and a poorer performance on the Confidence Index and Omissions Errors of the CPT. In contrast, no association between salivary $\mathrm{T}$ levels and clinical assessments was observed among boys with ADHD.

\section{$2 \mathrm{D} / 4 \mathrm{D}$ ratios and $\mathrm{ADHD}$}

We did not find a sexual difference in 2D/4D ratios among school-age children with ADHD in our cohort. Evidence generally indicates that $2 \mathrm{D} / 4 \mathrm{D}$ ratio of the right hand is lower in males compared with females among general population. ${ }^{41}$ However, the overall patterns of $2 \mathrm{D} / 4 \mathrm{D}$ ratio may vary across age, sex, and hand. ${ }^{42}$ As study sample contained ADHD patients and the sample size of girls was also small, the current result may not be comparable to previous literature. In both sexes, the 2D/4D ratios were not correlated with any clinical measure or neuropsychological performance. Several researchers have reported that the $2 \mathrm{D} / 4 \mathrm{D}$ ratio correlates inversely with ADHD symptoms in both healthy and clinical populations. ${ }^{16-19}$ However, some studies have failed to replicate such a correlation and challenge the hypothesis that fetal $\mathrm{T}$ exposure increases the risk of early ADHD..$^{20-22}$ The inconsistency between studies might be caused by sample diversity (eg, clinical or community sample, age distribution, and specific sex). Our study sample consisted of pure ADHD patients with a mean age of $8.7 \pm 2.0$ years, and these sample characteristics were similar to those of the sample enrolled by Lemiere et al; in fact, the findings in our study are generally in line with those of Lemiere et al. ${ }^{21}$ This phenomenon may reflect that subjects with ADHD genuinely differ from typically developed children in terms of the sex effect on this measure. In sum, we suggest that there was no significant association between $2 \mathrm{D} / 4 \mathrm{D}$ ratio and $\mathrm{ADHD}$ severity among our cohort of school-age children with ADHD.

\section{D/4D ratios and $\mathrm{DBD}$}

Patients with comorbid DBD (ODD or conduct disorder) had lower 2D/4D ratios than did their counterparts without the comorbidity. There was no evidence for an association between 2D/4D ratio and ODD scores for either sex. ODD and conduct disorder, which are characterized by temper tantrums, physical aggression, and other forms of defiance or resistance to authority, are the most common psychiatric comorbidities with ADHD. ${ }^{43}$ Several studies have investigated the potential association between $\mathrm{T}$ and DBD. For example, de Bruin et $\mathrm{al}^{44}$ observed that males with autistic spectrum disorders and those with ADHD or ODD had lower 2D/4D ratios than did males with an anxiety disorder. Roberts and Marte $^{19}{ }^{19}$ reported that there were no significant associations between right-hand 2D/4D ratios and ODD or total symptoms of DBD. Subsequently, Martel and Roberts ${ }^{45}$ demonstrated that high prenatal $\mathrm{T}$ exposure increases the risk of DBD symptoms in males who are susceptible to prenatal environmental stressors (eg, prenatal alcohol exposure). Prenatal T could influence the development of neural circuits that regulate affect and impulse control. ${ }^{23}$ Taken together with our results, we suggest that these findings support the hypothesis that excessive prenatal $\mathrm{T}$ exposure may result in a high risk of developing DBD among school-age children with ADHD.

\section{Salivary testosterone levels and ADHD}

We found that salivary $T$ levels were positively correlated with age, height, body weight, and BMI in boys, but this phenomenon was not observed in girls. The result herein is inconsistent with the findings reported by Clifton et $\mathrm{al},{ }^{46}$ in which salivary $\mathrm{T}$ levels are negatively correlated with BMI among British men (ages between 18 and 74 years and BMI $\geq 18.5$ ). We suggest that, different from the physiological effect in adult, peripheral $\mathrm{T}$ levels may be associated with physical development in male youths. ${ }^{10}$ Furthermore, our results show that, among ADHD patients, current salivary T levels are not significantly correlated with their behavioral symptoms and comorbidities. Some researchers have revealed a significant positive relationship between $T$ levels (either plasma or salivary) and the tendency toward DBD. ${ }^{27-29}$ Dorn et a ${ }^{30}$ did not find such a relationship, which is generally comparable with the findings in our study. The possible explanation is that $\mathrm{T}$ has been implicated in dominant behavior and muscular physiology change but does not necessarily cause aggression or externalized problem behaviors..$^{23,24}$ The findings in this study do not support the assumption that current $\mathrm{T}$ levels influence ADHD behavior.

\section{Salivary testosterone levels and neurocognitive functions}

Among the boys with ADHD, salivary T levels were not significantly correlated with neurocognitive functions. In contrast, among the girls in our cohort, salivary T levels seem to be beneficial for the PRI performance in the WISC-IV and may be detrimental for attention measured by the CPT. 
Bjork et $\mathrm{a}^{47}$ reported a positive relationship between $\mathrm{T}$ and impaired impulse control assessed using CPT among healthy women. In general, the CPT has been considered to be advantageous compared with other ADHD behavioral rating scales because it eliminates rater bias. ${ }^{48} \mathrm{We}$ assume that CPT may be more sensitive for detecting impaired attention than the scores of the SNAP-IV. We found that salivary T levels in girls were lower than those in boys. Girls with ADHD possibly were more susceptible to endogenous T exposure, which further influenced their neuropsychological performance.

The PRI in the WISC-IV mainly assesses nonverbal reasoning abilities and problem-solving skills. Some previous studies ${ }^{49-51}$ have investigated the potential influence of $\mathrm{T}$ on human cognitive function, but with contradictory results. Puts et $\mathrm{al}^{49}$ indicated that salivary $\mathrm{T}$ levels do not play a role in sex differences in spatial ability among young men and women. Shangguan and $\mathrm{Shi}^{50}$ suggested that the relationship between salivary $\mathrm{T}$ level and fluid intelligence varies based on participants' age. In prepubertal children, a significant association with salivary T levels and IQ was observed among boys, but not among girls. ${ }^{51} \mathrm{~A}$ brain imaging study revealed a positive association between $\mathrm{T}$ levels and activation of certain brain areas, including the inferior frontal lobe, the inferior parietal lobe, and the ventromedial prefrontal cortex. ${ }^{52}$ These brain areas manage nonverbal reasoning and visuospatial ability, which are considered superior in males relative to females. ${ }^{53}$ On the basis of these findings and our results, we suggest that the current $\mathrm{T}$ level may exert its neurodevelopmental effects and modify cognitive patterns, particularly among girls with ADHD.

\section{Limitations}

This study has several limitations: first, this study lacked a control group. Therefore, we could not compare the preor postnatal $\mathrm{T}$ levels among ADHD patients to those of healthy control subjects. Second, this study was performed with a cross-sectional design. The causal relationships between T exposure, DBD, and neurocognitive deficits remain unclear. In addition, this study used salivary $\mathrm{T}$ as a surrogate marker of postnatal $\mathrm{T}$ exposure. The mechanisms by which postnatal T exposure during patients' early childhood influences their current ADHD characteristics is unknown, and peripheral salivary $\mathrm{T}$ levels may not necessarily represent the $\mathrm{T}$ exposure in the central nervous system. Third, the sample size of the girls with ADHD was relatively small compared with the sample size of boys, which reduces the statistical power to detect potential correlations of $\mathrm{T}$ levels with clinical assessments. Fourth, because the analyses in this study were exploratory, correction of multiple testing was not performed. However, if Bonferroni correction was performed to adjust for multiple testing in the correlation matrix (Table 3), none of the significant findings would survive. Therefore, the findings in this study may suggest that only a subtle relationship exists between T and ADHD manifestations. Moreover, we collected only one saliva sample for each subject, lacking duplicates to perform further analysis. It is possible that the variations of $\mathrm{T}$ levels in saliva are massive and our result should be interpreted with caution. Finally, some important factors (eg, personality traits or prenatal alcohol exposure) have been reported to mediate relationships between $\mathrm{T}$ and ADHD psychopathology. ${ }^{18,45}$ These factors were not evaluated in this study.

\section{Conclusion}

We found that a higher level of prenatal $\mathrm{T}$ exposure (lower 2D/4D ratio) is associated with comorbid ODD or conduct disorder among patients with ADHD. Among boys with ADHD, neither prenatal $\mathrm{T}$ exposure nor current $\mathrm{T}$ levels correlated with ADHD clinical symptoms and neuropsychological performance. Among girls with ADHD, the current $\mathrm{T}$ level may exert a beneficial effect on nonverbal reasoning and visuospatial ability measured by the WISC-IV, but elevated $\mathrm{T}$ levels have a detrimental effect on attention function measured by the CPT. Further studies are warranted to clarify the neurobiological mechanisms underlying T's involvement in the pathogenesis of ADHD.

\section{Acknowledgments}

The authors would like to thank Professor Wei-Tsun Soong for granting us the use of the Chinese version of the K-SADS and Professor Shur-Fen Gau for granting our use of the Chinese version of the SNAP-IV. This work was supported by the Taiwan National Science Council (NSC 102-2314-B182A-009), the Taiwan Ministry of Science and Technology (MOST 103-2314-B-182A-017), and the Chang Gung Memorial Hospital Research Projects (CMRPG8E0561 and CMRPG8E0571).

\section{Disclosure}

The authors report no conflicts of interest in this work.

\section{References}

1. Polanczyk G, de Lima MS, Horta BL, Biederman J, Rohde LA. The worldwide prevalence of ADHD: a systematic review and metaregression analysis. Am J Psychiatry. 2007;164(6):942-948.

2. Rucklidge JJ. Gender differences in attention-deficit/hyperactivity disorder. Psychiatr Clin North Am. 2010;33(2):357-373. 
3. Hasson R, Fine JG. Gender differences among children with ADHD on continuous performance tests: a meta-analytic review. J Atten Disord. 2012;16(3):190-198.

4. Nussbaum NL. ADHD and female specific concerns: a review of the literature and clinical implications. J Atten Disord. 2012;16(2):87-100.

5. Wang LJ, Chen CK, Huang YS. Gender differences in the behavioral symptoms and neuropsychological performance of patients with attention-deficit/hyperactivity disorder treated with methylphenidate: A Two-Year Follow-up Study. J Child Adolesc Psychopharmacol. 2015; 25(6):501-508.

6. Martel MM, Klump K, Nigg JT, Breedlove SM, Sisk CL. Potential hormonal mechanisms of attention-deficit/hyperactivity disorder and major depressive disorder: a new perspective. Horm Behav. 2009;55(4):465-479.

7. Davies W. Sex differences in attention deficit hyperactivity disorder: candidate genetic and endocrine mechanisms. Front Neuroendocrinol. 2014;35(3):331-346.

8. Brunton PJ. Programming the brain and behaviour by early-life stress: a focus on neuroactive steroids. J Neuroendocrinol. 2015;27(6): 468-480.

9. Albin AK, Norjavaara E. Pubertal growth and serum testosterone and estradiol levels in boys. Horm Res Paediatr. 2013;80(2):100-110.

10. Auyeung B, Lombardo MV, Baron-Cohen S. Prenatal and postnatal hormone effects on the human brain and cognition. Pflugers Arch. 2013; 465(5):557-571.

11. Juraska JM, Sisk CL, DonCarlos LL. Sexual differentiation of the adolescent rodent brain: hormonal influences and developmental mechanisms. Horm Behav. 2013;64(2):203-210.

12. Morris JA, Jordan CL, Breedlove SM. Sexual differentiation of the vertebrate nervous system. Nat Neurosci. 2004;7(10):1034-1039.

13. Manning JT, Scutt D, Wilson J, Lewis-Jones DI. The ratio of 2nd to 4th digit length: a predictor of sperm numbers and concentrations of testosterone, luteinizing hormone and oestrogen. Hum Reprod. 1998; 13(11):3000-3004.

14. Cohen-Bendahan CC, van de Beek C, Berenbaum SA. Prenatal sex hormone effects on child and adult sex-typed behavior: methods and findings. Neurosci Biobehav Rev. 2005;29(2):353-384.

15. Manning J, Kilduff L, Cook C, Crewther B, Fink B. Digit ratio (2D:4D): a biomarker for prenatal sex steroids and adult sex steroids in challenge situations. Front Endocrinol (Lausanne). 2014;5:9.

16. Stevenson JC, Everson PM, Williams DC, Hipskind G, Grimes M, Mahoney ER. Attention deficit/hyperactivity disorder (ADHD) symptoms and digit ratios in a college sample. Am J Hum Biol. 2007; 19(1):41-50.

17. James WH. Further evidence that some male-based neurodevelopmental disorders are associated with high intrauterine testosterone concentrations. Dev Med Child Neurol. 2008;50(1):15-18.

18. Martel MM. Conscientiousness as a mediator of the association between masculinized finger-length ratios and attention-deficit/hyperactivity disorder (ADHD). J Child Psychol Psychiatry. 2009;50(7):790-798.

19. Roberts BA, Martel MM. Prenatal testosterone and preschool disruptive behavior disorders. Pers Individ Dif. 2013;55(8):962-966.

20. Mahone EM. Why fewer females than males are diagnosed with attention-deficit-hyperactivity disorder: it might not be hormones. Dev Med Child Neurol. 2010;52(9):790-791.

21. Lemiere J, Boets B, Danckaerts M. No association between the 2D:4D fetal testosterone marker and multidimensional attentional abilities in children with ADHD. Dev Med Child Neurol. 2010;52(9):e202-e208.

22. Liu J, Portnoy J, Raine A. Association between a marker for prenatal testosterone exposure and externalizing behavior problems in children. Dev Psychopathol. 2012;24(3):771-782.

23. Nguyen TV, McCracken JT, Albaugh MD, Botteron KN, Hudziak JJ, Ducharme S. A testosterone-related structural brain phenotype predicts aggressive behavior from childhood to adulthood. Psychoneuroendocrinology. 2016;63:109-118.

24. Rice TR. Postnatal testosterone may be an important mediator of the association between prematurity and male neurodevelopmental disorders: a hypothesis. Int J Adolesc Med Health. 2017;29(2):pii.
25. Ohzeki T, Manella B, Gubelin-De Campo C, Zachmann M. Salivary testosterone concentrations in prepubertal and pubertal males: comparison with total and free plasma testosterone. Horm Res. 1991;36(5-6):235-237.

26. Herguner S, Harmanci H, Toy H. Attention deficit-hyperactivity disorder symptoms in women with polycystic ovary syndrome. Int $J$ Psychiatry Med. 2015;50(3):317-325.

27. Scerbo AS, Kolko DJ. Salivary testosterone and cortisol in disruptive children: relationship to aggressive, hyperactive, and internalizing behaviors. J Am Acad Child Adolesc Psychiatry. 1994;33(8):1174-1184.

28. Pajer K, Tabbah R, Gardner W, Rubin RT, Czambel RK, Wang Y. Adrenal androgen and gonadal hormone levels in adolescent girls with conduct disorder. Psychoneuroendocrinology. 2006;31(10):1245-1256.

29. Yu YZ, Shi JX. Relationship between levels of testosterone and cortisol in saliva and aggressive behaviors of adolescents. Biomed Environ Sci. 2009;22(1):44-49.

30. Dorn LD, Kolko DJ, Susman EJ, et al. Salivary gonadal and adrenal hormone differences in boys and girls with and without disruptive behavior disorders: contextual variants. Biol Psychol. 2009;81(1):31-39.

31. Biro FM, Pinney SM, Huang B, et al. Hormone changes in peripubertal girls. J Clin Endocrinol Metab. 2014;99(10):3829-3835.

32. Kaufman J, Birmaher B, Brent D, et al. Schedule for Affective Disorders and Schizophrenia for School-Age Children-Present and Lifetime Version (K-SADS-PL): initial reliability and validity data. J Am Acad Child Adolesc Psychiatry. 1997;36(7):980-988.

33. Gau SF, Soong WT. Psychiatric comorbidity of adolescents with sleep terrors or sleepwalking: a case-control study. Aust N Z J Psychiatry. 1999;33(5):734-739.

34. Yang P, Cheng CP, Chang CL, Liu TL, Hsu HY, Yen CF. Wechsler Intelligence Scale for Children 4th edition-Chinese version index scores in Taiwanese children with attention-deficit/hyperactivity disorder. Psychiatry Clin Neurosci. 2013;67(2):83-91.

35. Baron IS. Test review: Wechsler Intelligence Scale for Children-Fourth Edition (WISC-IV). Child Neuropsychol. 2005;11(5):471-475.

36. Bussing R, Fernandez M, Harwood M, et al. Parent and teacher SNAP-IV ratings of attention deficit hyperactivity disorder symptoms: psychometric properties and normative ratings from a school district sample. Assessment. 2008;15(3):317-328.

37. Gau SS, Shang CY, Liu SK, et al. Psychometric properties of the Chinese version of the Swanson, Nolan, and Pelham, version IV scaleparent form. Int J Methods Psychiatr Res. 2008;17(1):35-44.

38. Gau SS, Lin CH, Hu FC, et al. Psychometric properties of the Chinese version of the Swanson, Nolan, and Pelham, Version IV Scale-Teacher Form. J Pediatr Psychol. 2009;34(8):850-861.

39. Conners CK. The computerized continuous performance test. Psychopharmacol Bull. 1985;21(4):891-892.

40. Conners CK. Conners' Continuous Performance Test II (CPTII) for Windows Technical Guide and Software Manual. North Tonwanda, NY: MHS; 2004.

41. Xu Y, Zheng Y. The digit ratio (2D:4D) in China:a meta-analysis. Am J Hum Biol. 2015;27(3):304-309.

42. Wong WI, Hines M. Interpreting digit ratio (2D:4D)-behavior correlations: 2D:4D sex difference, stability, and behavioral correlates and their replicability in young children. Horm Behav. 2016;78:86-94.

43. Connor DF, Steeber J, McBurnett K. A review of attention-deficit/ hyperactivity disorder complicated by symptoms of oppositional defiant disorder or conduct disorder. J Dev Behav Pediatr. 2010;31(5): $427-440$.

44. de Bruin EI, Verheij F, Wiegman T, Ferdinand RF. Differences in finger length ratio between males with autism, pervasive developmental disorder-not otherwise specified, ADHD, and anxiety disorders. Dev Med Child Neurol. 2006;48(12):962-965.

45. Martel MM, Roberts BA. Prenatal testosterone increases sensitivity to prenatal stressors in males with disruptive behavior disorders. Neurotoxicol Teratol. 2014;44:11-17.

46. Clifton S, Macdowall W, Copas AJ, et al. Salivary testosterone levels and health status in men and women in the British general population: findings from the Third National Survey of Sexual Attitudes and Lifestyles (Natsal-3). J Clin Endocrinol Metab. 2016;101(11):3939-3951. 
47. Bjork JM, Moeller FG, Dougherty DM, Swann AC. Endogenous plasma testosterone levels and commission errors in women: a preliminary report. Physiol Behav. 2001;73(1-2):217-221.

48. Madaan V, Daughton J, Lubberstedt B, Mattai A, Vaughan BS, Kratochvil CJ. Assessing the efficacy of treatments for ADHD: overview of methodological issues. CNS Drugs. 2008;22(4):275-290.

49. Puts DA, Cardenas RA, Bailey DH, Burriss RP, Jordan CL, Breedlove SM. Salivary testosterone does not predict mental rotation performance in men or women. Horm Behav. 2010;58(2):282-289.

50. Shangguan F, Shi J. Puberty timing and fluid intelligence: a study of correlations between testosterone and intelligence in 8- to 12-year-old Chinese boys. Psychoneuroendocrinology. 2009;34(7):983-988.
51. Ostatnikova D, Celec P, Putz Z, et al. Intelligence and salivary testosterone levels in prepubertal children. Neuropsychologia. 2007;45(7): 1378-1385.

52. Schoning S, Engelien A, Kugel H, et al. Functional anatomy of visuo-spatial working memory during mental rotation is influenced by sex, menstrual cycle, and sex steroid hormones. Neuropsychologia. 2007;45(14):3203-3214.

53. Rizk-Jackson AM, Acevedo SF, Inman D, Howieson D, Benice TS, Raber J. Effects of sex on object recognition and spatial navigation in humans. Behav Brain Res. 2006;173(2):181-190.

\section{Publish your work in this journal}

Neuropsychiatric Disease and Treatment is an international, peerreviewed journal of clinical therapeutics and pharmacology focusing on concise rapid reporting of clinical or pre-clinical studies on a range of neuropsychiatric and neurological disorders. This journal is indexed on PubMed Central, the 'PsycINFO' database and CAS, and is the official journal of The International Neuropsychiatric Association (INA). The manuscript management system is completely online and includes a very quick and fair peer-review system, which is all easy to use. Visit http://www.dovepress.com/testimonials.php to read real quotes from published authors.

Submit your manuscript here: http://www.dovepress.com/neuropsychiatric-disease-and-treatment-journal 